\title{
INTERAÇÃO, AUTORIA E ENVOLVIMENTO NO GÊNERO EDITORIAL: UMA ANÁLISE SISTÊMICO-FUNCIONAL
}

\author{
INTERACTION, AUTHORSHIP AND ENGAGEMENT IN EDITORIAL DISCOURSE \\ GENRE: A SYSTEMIC FUNCTIONAL ANALYSIS
}

\author{
Lucélio Dantas de Aquino \\ Instituto Metrópole Digital \\ Universidade Federal do Rio Grande do Norte \\ lucelioaquino@imd.ufrn.br
}

RESUMO: Este artigo apresenta parte do estudo desenvolvido na pesquisa de mestrado Mecanismos de construção de sentidos no gênero editorial: aspectos verbais e visuais (AQUINO, 2010). O recorte escolhido para compor esse texto diz respeito à análise sobre interação, autoria e envolvimento no gênero editorial. Para tanto, assumimos os postulados da Linguística Sistêmico-Funcional (HALLIDAY, 1985; 2004; BUT et al., 2001; GHIO; FERNÁNDEZ, 2008; entre outros), especificamente, os que concernem à metafunção interpessoal da linguagem. Os resultados revelam que os recursos léxico-gramaticais como sujeito nominalizado, marcas desinenciais, pronomes pessoais, possessivos e de tratamento realizam interação entre os envolvidos nesse contexto de situação, uma vez que constatamos graus diferentes de formalidade, bem como, a atenuação do caráter impessoal deste gênero devido às marcas de autoria.

PALAVRAS-CHAVE: Metafunção interpessoal; Interação; Autoria; Envolvimento; Gênero editorial.

ABSTRACT: This paper presents part of a study developed by the master's level research Mecanismos de construção de sentidos no gênero editorial: aspectos verbais e visuais (AQUINO, 2010). The chosen path to compound this text concerns to the analysis about interaction, authorship and engagement in the editorial discourse genre. For this purpose, we assume the postulates from Systemic Functional Linguistics (HALLIDAY, 1985; 2004; BUT et al., 2001; GHIO; FERNÁNDEZ, 2008), especially those which concern to the language interpersonal metafunction. The findings reveal that the lexical and grammar resources like nominalized subject, desinential marks, personal, possessive and treatment pronouns realize interaction facets among the participants involved in this situational context, since we found different formality degrees as well as the attenuation of the impersonal character due to the authorship marks in the editorial discourse genre.

KEYWORDS: Interpersonal Metafunction; Interaction; Authorship; Engagement; Editorial Genre.

\section{CONSIDERAÇÕES INICIAIS}

O presente artigo constitui-se de um excerto de nossa dissertação de mestrado (AQUINO, 2010), a qual versou sobre a Linguística Sistêmico-Funcional - LSF - e a Multimodalidade Discursiva.

Nela, discutimos acerca da interação no gênero editorial, especificamente utilizado por jornais e revistas para expor um ponto de vista sobre determinado assunto, ou veículo de comunicação que está em voga na sociedade. Sendo, portanto, opinativo, o editorial é produzido com base na argumentação para persuadir os leitores a aderirem ao que nele foi ou 
está expresso ou, pelo menos, aceitar tal posicionamento. Além disso, o editorial é um gênero dinâmico que apresenta variações em sua funcionalidade, pois, dependendo da instituição que o veicula, ele poderá exprimir uma opinião sobre determinado fato (editorial padrão), apresentar o suporte que o conduz (editorial de apresentação) e/ou unir as duas funções anteriores, opinando sobre algo e apresentando o suporte, além de ser preventivo, dependendo do propósito comunicativo (editorial misto). Outro ponto relevante na definição de editorial, conforme os manuais de redação jornalística, é que ele deve ser neutro, imparcial e impessoal, haja vista representar a opinião institucional.

Desta feita, buscamos, neste texto - o gênero editorial -, com base na metafunção interpessoal da linguagem, discutida por Halliday $(1985 ;$ 2004), entre outros pesquisadores e estudiosos da LSF, analisar a interação, autoria e envolvimento nesse gênero. Para tanto, como a pesquisa de mestrado desenvolveu a análise de editoriais de duas revistas de circulação nacional (Época e Veja), tomaremos excertos de onze exemplares dos quarenta e oito editoriais que compuseram o corpus da dissertação para exemplificar nossas análises. Desses onze editoriais, sete são da revista Época e quatro são da revista Veja. São eles:

Quadro 1 Códigos dos editoriais a serem analisados.

\begin{tabular}{|l|c|c|c|c|}
\hline \multicolumn{1}{|c|}{ Texto } & $\begin{array}{c}\text { Sigla da } \\
\text { revista }\end{array}$ & $\begin{array}{c}\text { No de ordem } \\
\text { de coleta }\end{array}$ & $\begin{array}{c}\text { Ano de } \\
\text { publicação }\end{array}$ & Código \\
\hline Profissionais premiados & EP & 01 & 03 & EP0103 \\
\hline Insegurança para todos & EP & 05 & 03 & EP0503 \\
\hline Políticos e críticos & EP & 09 & 03 & EP0903 \\
\hline Entre o amor e a guerra & EP & 01 & 09 & EP0109 \\
\hline Os bancos daqui - e os lá de fora & EP & 05 & 09 & EP0509 \\
\hline O congresso, o câncer e a gripe suína & EP & 09 & 09 & EP0909 \\
\hline O Estado continua sendo o problema & EP & 11 & 09 & EP1109 \\
\hline Pela porta estreita & VE & 05 & 03 & VE0503 \\
\hline Duas capas, a mesma Veja & VE & 08 & 03 & VE0803 \\
\hline Otimismo contra a crise & VE & 05 & 09 & VE0509 \\
\hline Continuamos no mesmo lugar & VE & 10 & 09 & VE1009 \\
\hline
\end{tabular}

Fonte: Autor

No que concerne ao código, optamos por manter os que haviam sido estabelecidos na dissertação, ou seja, os códigos são compostos pela sigla da revista, pelo número de ordem da coleta do corpus, posto que, realizamos a coleta de 12 editoriais a cada ano e, por último, o ano de publicação do texto, podendo os editoriais serem definidos pelo 03, referente a 2003, ou 09, referente ao ano de 2009 (período que compreendeu a coleta do corpus da dissertação). Quanto aos exemplos, estes são apresentados em ordem crescente, identificados por um número entre colchetes, contemplando períodos dos textos em que a oração apresenta as palavras que servirão às análises. Para efeito de identificação, as palavras serão destacadas em negrito e com sublinhado na oração em que elas aparecem, pois a oração é a unidade básica de análise para a LSF, conforme afirma Halliday (2004).

Por uma questão de sistematização, este trabalho está dividido em cinco partes: na primeira, considerações iniciais, fazemos a apresentação do trabalho, definindo o objetivo e algumas questões metodológicas que orientam o restante do texto; na segunda, fundamentos teóricos, apresentamos os postulados que respaldam as análises; na terceira, interação, autoria $e$ envolvimento, analisamos os recursos léxico-gramaticais que estabelecem a interpessoalidade no gêneros editorial, bem como seus efeitos de sentido nos textos; na quarta, apresentamos as considerações finais; e na quinta e última parte, as referências teóricas consultadas, bem 
como as referências dos editoriais analisados, haja vista esses últimos, por uma questão de espaço, não poderem ser apresentados na íntegra no corpo do artigo.

\section{FUNDAMENTOS TEÓRICOS}

\subsection{Linguística Sistêmico - Funcional}

M. A. K. Halliday é o maior expoente da Linguística Sistêmico-Funcional - LSF. Uma corrente teórica de base funcionalista que entende que o texto e o contexto devem ser levados em consideração em uma abordagem semântico-funcional da linguagem.

Eggins (2004, p. 20-21) afirma que a LSF pode ser descrita como uma aproximação semântico-funcional da linguagem que explora como as pessoas usam a linguagem em diferentes contextos, e como a linguagem é estruturada para uso como sistema semiótico. Desse modo, falar em texto é falar da linguagem em uso, em interação, em escolhas que fazemos diante de um repertório de possibilidades que a língua oferece.

Nessa perspectiva, Halliday (2004) assume a corrente sistêmico-funcional como uma teoria que observa a língua enquanto escolha, ou seja, sempre que se usa determinada construção linguística estamos empregando escolhas que constroem o discurso, com o efeito de provocar a significação que se deseja sobre os interlocutores. Assim sendo, sempre que houver uma interação social na qual as pessoas concretizem seus dizeres por meio de textos (falados ou escritos) e na qual se busquem realizar sentidos com base no exposto, será disso que a LSF se ocupará.

Dessa maneira, um texto, para existir, tem de fazer parte de uma cultura e realizar funções específicas. De acordo com Butt et al. (2001, p. 3), a combinação do contexto de cultura e contexto de situação resulta em diferenças e semelhanças entre uma parte de linguagem e outra, ou seja, dependendo do contexto de cultura e do contexto de situação nos quais usuários da linguagem se comunicam por meio de textos, diversas formas textuais se fazem disponíveis na cultura e, para isso, escolhas entre essas formas devem ser feitas para que a linguagem cumpra com o seu propósito comunicativo.

Conforme Butt et al. (2001, p. 3), podemos descrever o contexto de cultura como a soma dos diversos significados possíveis de significar em uma cultura particular. Por este viés, ao adentrarmos em um campo de atividade humana, estamos inseridos em uma cultura que, por meio da linguagem, realiza significados, sendo estes frutos de escolhas que a cultura disponibiliza. Vale lembrar que no contexto de cultura é que os gêneros são reconhecidos e legitimados pelos interactantes da linguagem.

O contexto de situação é a outra forma de caracterizar as escolhas que fazemos para realizar interações sociais por meio da linguagem. Enquanto o contexto de cultura realiza-se por meio do gênero, compreendendo todo o sistema semântico da linguagem, o contexto de situação realiza-se por meio do registro e é uma representação abstrata do entorno em termos de categorias gerais que tem importância para o texto (GHIO; FERNÁNDEZ, 2008).

Butt et al. (2001) afirmam que a LSF se refere a três aspectos do contexto de situação que desempenham funções específicas no uso da linguagem. Esses aspectos são essenciais na composição dos discursos que permeiam nossa sociedade e, consequentemente, são também características de uma cultura, por isso a indissociabilidade dos dois contextos: cultura e 
situação. Assim, o contexto de situação realiza-se por meio dos aspectos campo, relação e modo, os quais, de acordo com Ghio e Fernández (2008, p. 45), caracterizam-se como:

1)Campo: el uso que se hace de la lengua varía según los diferentes tipos de acción social. En parte, las acciones tienen que ver con el asunto, de manera que el campo del uso discursivo incluye también el tópico. Por lo tanto, el campo discursivo es antes que nada un campo de acción. Durante la acción de jugar al fútbol, el fútbol pude ser el tópico de la conversación. No obstante, la acción verbal durante el juego es distinta de la discusión sobre el fútbol en el bar. Esa diferencia se expresa mediante el concepto de campo de discurso.

2)Relação: refiere al grado de formalidad entre los participantes de la interacción, tales como profesor/alumnos; vendedor/cliente; médico/paciente; padres/hijos; los chicos que interactúan en grupos de pares, las personas que se encuentran en el colectivo. La denominación genérica de este tipo de relaciones es la de rol. Las conferencias, los servicios religiosos, las fiestas constituyen escenarios definidos en los que se establecem relaciones de rol institucionalizadas, a las que Halliday caracteriza como modelos estabilizados del tenor del discurso (1978:222).

3)Modo del discurso: este término se aplica para referirse al medio en que se realiza el discurso o texto: oral o escrito, pero también tiene que ver con los canales retóricos que se emplean: audiovisual, solo áudio (por ejemplo, una conversación telefónica). También refiere al modo en que se organiza y progresa el flujo de la información. (GHIO; FERNÁNDEZ, 2008, p. 45, grifos das autoras).

Desse modo, retomamos o conceito principal da LSF para endossar o propósito dos aspectos campo, relação e modo na linguagem: sendo a linguagem composta por uma rede de sistemas, essas três variáveis vão ativar uma rede semântica de escolhas que servirão aos interlocutores de uma dada comunidade linguística a realizarem, através de suas escolhas e do ambiente em que está sendo constituído o registro, uma situação interativa que, por meio da cultura permeadora deste espaço, receberá a denominação de gênero.

Nesse sentido, contextos e variáveis configuram-se como indispensáveis aos estudos sistêmico-funcionais, haja vista que os contextos afetam diretamente as escolhas léxicosemânticas realizadas. Isso se reflete nas três funções da linguagem propostas por Halliday (1985), as metafunções da linguagem.

\subsection{Metafunções da Linguagem}

Partindo do princípio de que as escolhas que fazemos estão contextualmente ligadas aos aspectos constituintes da situação e que estes determinam essas escolhas, justamente por refletirem as funções que constituem os propósitos principais da linguagem, devemos entender com mais clareza o papel de cada uma dessas funções. Lembramos que as escolhas linguísticas são materializadas na léxico-gramática e realizam semanticamente sentidos. Nesta acepção, a linguagem, para a LSF, se realiza por meio de metafunções.

Nas palavras de Halliday (2004), as funções básicas da linguagem são duas: uma que produz os sentidos da experiência humana e uma que representa as relações sociais. Para ele, a primeira metafunção, aquela que constrói as experiências humanas, é chamada de ideacional. Ela é responsável por nomear coisas, interpretando-as em categoriais, por conseguinte, essas 
categoriais são, mais adiante, interpretadas em taxonomias. Nesse sentido, a linguagem provê uma teoria da experiência humana e certos recursos da léxico-gramática são dedicados a esta função.

A segunda metafunção a que se refere o autor é a interpessoal. Segundo ele, essa função desempenha as variadas relações pessoais e sociais com as outras pessoas que nos rodeiam. A oração, nessa metafunção, é vista, além da representação de algum processo com seus participantes e circunstâncias, como proposição ou proposta a partir das quais informamos, questionamos, damos ordens ou fazemos ofertas, além de expressarmos nossa avaliação e atitude em relação a quem estamos nos dirigindo ou sobre o qual estamos falando. Desse modo, Halliday (2004, p. 29-30), afirma que, se a função ideacional da gramática é linguagem como reflexão, esta é linguagem como ação.

Segundo o autor, essas são as duas funções básicas da linguagem e cada uma desempenha significados diferentes em uma oração, configurando duas redes de sistemas distintos. Nesse sentido, toda mensagem é sobre algo e endereçada a alguém. E, pela necessidade de organização dessas funções no texto, outra função é emanada da linguagem - a metafunção textual. O seu papel na linguagem está em organizar o fluxo discursivo em seus movimentos sucessivos de interação e manter a coesão no texto (HALLIDAY, 2004).

Nessa perspectiva, é na oração que se conjugam essas metafunções que se projetam verbalmente para produzir os sentidos desejados. Dessa forma, semântica e léxico-gramática se organizam em conjunto para realizar as metafunções, fornecendo o repertório linguístico do qual o produtor de um texto escolherá o que é pertinente a sua produção. Sendo assim, para que possamos realizar esse estudo sobre interação, autoria e envolvimento no gênero editorial, nos respaldamos nas metafunções da linguagem da LSF, tomando, metodologicamente, a metafunção interpessoal como base, haja vista nosso interesse em perceber as relações que o editorialista mantém com o público e com o próprio texto.

\subsubsection{Recursos interpessoais da linguagem}

A metafunção interpessoal da linguagem está associada ao aspecto relação que compõem a tríade constituinte do contexto de situação. Esse aspecto é responsável pelo grau de formalidade que se estabelece nas interações sociais e pelas expressões dos papéis e das atitudes dos participantes dessas interações. Segundo Halliday e Mathiessen (1997, online):

The interpersonal metafunction is concerned with the interaction between speaker and addressee(s), the grammatical resources for enacting social roles in general, and speech roles in particular, in dialogic interaction; i.e. for establishing, changing, and maintaining interpersonal relations. (grifos dos autores).

Nesse sentido, além de graus de formalidade, essa metafunção desempenha papéis sociais como estabelecer, trocar e manter relações entre os falantes de uma língua. Em uma interação, os falantes/escritores realizam um papel em particular e atribuem a seus ouvintes/leitores um outro papel complementar que é desejado pelo autor, pois é característica dessa metafunção estabelecer trocas, havendo, portanto, uma alternância dos papéis de oferecer e pedir bens e serviços (propostas) ou informações (proposições). 
Por um lado, ao utilizar a linguagem como bens e serviços, o locutor visa a influenciar o comportamento de alguém ou a atingir um determinado objetivo por meio das escolhas que realiza. A este interesse do locutor pode ser conferida a aceitação ou a rejeição, obedecer ou desobedecer ao que por ele foi enunciado. Por outro lado, quando o papel é de informação, o uso da linguagem é de responsabilidade dos dois agentes da situação. Desse modo, ao utilizar a linguagem como informação, o locutor dará e pedirá informação. Isso se dá através de afirmações e/ou interrogações, fornecendo a informação para que o outro envolvido na situação tome conhecimento, podendo esse outro optar por não responder ou contestar a informação. Assim, a interação fica marcada no discurso proferido por meio de elementos léxico-gramaticais escolhidos em meio ao sistema de modo que a língua oferece aos seus falantes, isto é, a ser usada como troca de significados entre os interlocutores.

Mas, para que possamos reconhecer na língua os elementos que realizam a interação devemos entender um pouco dos sistemas responsáveis por esta metafunção. De acordo com a LSF, a metafunção interpessoal realiza-se pelo sistema de modo e pelo sistema de modalidade. $\mathrm{O}$ primeiro, como já dissemos, estabelece as relações de papéis entre escritor/leitor; e o segundo carrega o valor de verdade da mensagem escrita e a responsabilidade do escritor sobre o que está materializado.

Martin et al. (1997), afirmam que o sistema de modo é o recurso gramatical responsável para se perceber um movimento interativo no diálogo. Segundo esses autores, a distinção básica dentro do sistema gramatical de modo está entre os tipos de modo imperativo e indicativo. Com o tipo indicativo tem-se uma distinção adicional entre os tipos declarativos e interrogativos. Sendo assim, este conjunto compõe o que por eles é chamado de tipos básicos de modo.

Em uma interação, esses tipos de modo são realizados através das escolhas que os usuários da linguagem fazem a partir de uma rede de sistemas que lhes é disponibilizado. Assim, conforme afirmam Ghio e Fernández (2008, p. 123) "Al realizar selecciones en el sistema de modo el hablante asume un rol discursivo y asigna un rol complementario al oyente: el que ofrece/el que acepta ou rechaza un ofrecimiento; el que ordena algo/el que cumple la orden; el que pregunta/el que responde"(grifo das autoras).

Portanto, essas relações entre os participantes é que vão construir os diálogos e, consequentemente, os sucessivos movimentos de interação. Sendo assim, o sistema de modo se realiza por duas categorias gramaticais, que são: as propostas e as proposições, conforme aludido anteriormente. As propostas são intercâmbios de bens e serviços que podem ser oferecidos, aceitados, ou recusados, ou ordenados, ou seja, as propostas se realizam por meio do oferecimento quando o propósito é dar algo, e por meio da ordem quando se intui em ordenar, exortar ou suplicar. Já as proposições estão ligadas à troca de informação e se realizam por meio das orações declarativas ou das orações interrogativas.

Ainda de acordo com Ghio e Fernández (2008), ao oferecimento, à ordem, às declarativas e às perguntas se associam um conjunto de respostas desejáveis ou esperadas (que implicam apoio à proposta ou à proposição do falante) ou de alternativas para não acreditar (que implicam a possibilidade do ouvinte de questionar ou confrontar a proposta ou a proposição do falante). Através destas funções de demanda e oferta realizadas pela linguagem, verificamos a constante interação na linguagem e os papéis que os participantes ocupam na interação. 
Quanto ao sistema de modalidade, entende-se na LSF, segundo Halliday (2004), que esse sistema atua como um avaliador em uma região de incerteza sobre o que está sendo expresso pelo orador, ou sobre o que é pedido para o ouvinte expressar; a modalidade realiza uma avaliação da validez do que é dito. Segundo o autor, a modalidade, quando empregada na linguagem, opera em graus intermediários, uma vez que representa/demonstra apreciação sobre o que se está dizendo. Diz-se, portanto, que são graus intermediários por estarem entre os polos do 'sim' e do 'não', revelando indeterminação como 'às vezes' ou 'talvez'. Esses graus de significação são realizados por meio da escolha de recursos específicos que constroem significados de aproximação, afastamento, credibilidade, relevância, etc.

Os sistemas de modo e de modalidade, na língua portuguesa, são realizados por recursos léxico-gramaticais específicos, tais como: sujeito, pronomes, advérbios, adjetivos, auxiliares modais, interrogações, entre outros. Todavia, como nossa intenção é analisar os recursos que estabelecem interação, autoria e envolvimento no gênero editorial, deter-nos-emos aos seguintes recursos: sujeito, pronome possessivo e pronome de tratamento.

\section{a) Sujeito}

Conforme Halliday (2004), o sujeito é o responsável pelo restante de uma proposição, servindo de referência para uma possível afirmação ou negação da informação, sendo assim, a responsabilidade do sujeito consiste em fazer com que a oração funcione como um evento interativo. Em uma oração, o sujeito é acompanhado do verbo e do restante da oração, configurando o que se chama, na LSF, de estrutura do modo. Sujeito e finito formam o bloco modal e os demais elementos formam o restante. Assim, a oração gira em torno do sujeito, por isso ele é responsável por estabelecer o intercâmbio de informação na oração.

O sujeito para a LSF é visto assim como na concepção da Gramática Tradicional (GT). Tomando por base a gramática da língua portuguesa, na voz de Bechara (2004, p. 409), "chama-se sujeito à unidade ou sintagma nominal que estabelece uma relação predicativa com o núcleo verbal para constituir uma oração". Essa afirmação do gramático nos fornece a ideia de que o sujeito é um elemento nominalmente explícito na oração. Nesse sentido, o sujeito nominal é visto como aquele que pratica a ação em um dado contexto.

Outras formas de perceber o sujeito na oração são pelas formas pronominais, como, por exemplo, os pronomes retos e, também, pelas desinências verbais de número e pessoa, ou como chamamos em uma análise morfológica, os morfemas que indicam os sujeitos gramaticais. Com relação às desinências, são tomadas como formas de marcação do sujeito no discurso $0-O$ e o $-m o s, 1^{\mathrm{a}}$ pessoa do singular $(P 1 s)$ e $1^{\mathrm{a}}$ pessoa do plural $(P 1 p)$, respectivamente.

Sobre a questão pronominal, entendemos que a utilização dos pronomes retos (eu, tu, ele, nós, vós, eles) atua na linguagem como forma de interação, podendo manifestar a presença do falante/produtor de um texto e compartilhar a informação como sendo de consenso geral. Sendo assim, estes pronomes, em uma perspectiva interpessoal, promovem no texto a marcação da pessoa gramatical.

Outro recurso léxico-gramatical que evidencia a pessoa no discurso é a desinência verbal (). A desinência é encontrada nos morfemas de número e pessoa dos verbos conjugados. Acerca disso, tomamos por base a ideia de elipse do sujeito que, segundo Halliday (2004), em uma estrutura modal, elementos podem se fazer ausentes em uma oração sem quebrar a ordem 
textual. Isso acontece com o sujeito e, como já dissemos, toda oração gira em torno de um sujeito, mas é comum que este apareça elíptico, podendo ser recuperado por meio das desinências ${ }^{1}$. Portanto, as desinências verbais também marcam, assim como os pronomes retos, a voz do autor em um texto, ou melhor, indicam a pessoa gramatical do discurso $P 1 s$ ou Plp.

Sob essa ótica, quando, no discurso, a pessoa gramatical muda da P1s para a P1p, na variante culta da língua portuguesa, mudamos a conjugação do verbo. Isso implica diretamente nas relações sociais e comunicativas que se realizam entre os usuários da linguagem, uma vez que no singular o processo verbal tem um referente particular e quando a desinência aponta para o plural, subentende-se que, além do orador, existem outros interlocutores presentes no discurso. Dessa maneira, por essa concordância entre o sujeito e a forma conjugada do verbo é que Butt et al. (2001) afirma existir fortes sinais da relação Sujeito-finito, haja vista esse último (o verbo) refletir o primeiro (sujeito), ou seja, aquele que enuncia, ou sobre quem é falado no enunciado.

\section{b) Pronomes possessivos}

Os pronomes possessivos, especificamente os de P1p, segundo Souza (2007), manifestam a autoria em um texto. Desse, modo, são responsáveis também por coadunar os participantes do discurso na enunciação proferida. Esses pronomes, na gramática da língua portuguesa, são aqueles que indicam posse. Mas, como essa não é a única função de um pronome possessivo. Como na LSF toda significação parte de um contexto, entendemos que os pronomes possessivos são elementos interativos que unem os participantes em um texto, fazendo-os agir na mesma direção. E, no caso do editorial, servem também como recurso de persuasão, já que aquilo que é informado no gênero pode ser colocado, pelo pronome possessivo, como sendo o pensamento de toda a sociedade.

\section{c) Pronomes de tratamento}

Os pronomes de tratamento são responsáveis por materializar no texto o participante externo, no caso, o leitor, estabelecendo, portanto, uma relação dialógica e mais próxima com ele. $\mathrm{Na}$ GT, esses pronomes são apresentados e discutidos no tópico dos pronomes pessoais. Bechara (2004, p. 165) coloca-os como "formas substantivas de tratamento" ou "formas pronominais de tratamento", sendo o pronome você colocado nessa segunda categoria. Ainda sobre os pronomes de tratamento (você, o senhor, a senhora, entre outros), o gramático aponta para o fato de que eles são formas indiretas de tratamento "da $2^{\mathrm{a}}$ pessoa que levam o verbo para a $3^{\mathrm{a}}$ pessoa".

Portanto, esses elementos são utilizados pelos produtores de um texto com vistas a indicar a pessoa gramatical que fala, ou com quem se fala. Nessa perspectiva, os pronomes possessivos e pronomes de tratamento atendem a metafunção interpessoal que externa o modo como a linguagem, com base nas escolhas que são feitas em contextos de situação, estabelece relação entre os participantes de uma determinada interação social, refletindo, principalmente, no grau de formalidade desta interação.

\footnotetext{
${ }^{1}$ Embora tenhamos tomado o caso da elipse do sujeito de Halliday (2004) para falar das desinências verbais, isto não implica dizer que as desinências são uma forma de materializar elipticamente o sujeito na oração. A elipse, na língua portuguesa, é considerada como "a omissão de um termo facilmente subentendido por faltar onde normalmente aparece, ou por ter sido anteriormente enunciado ou sugerido, ou ainda por ser depreendido pela situação, ou contexto" (BECHARA, 2004, p. 592).
} 


\section{INTERAÇÃO, AUTORIA E ENVOLVIMENTO}

\subsection{Sujeito Nominalizado}

Como nos propomos a observar o sujeito como marca de interação no gênero editorial, buscamos no corpus o sujeito representante da instituição, ou seja, adotamos como critério o sujeito representado no nome das revistas - VEJA e ÉPOCA.

Apesar da aparente impessoalidade e da opinião institucional, os sujeitos aparecem no texto, ainda que esta não seja a pretensão do autor, para organizar o sucesso da interação. A respeito disso, observemos os exemplos que seguem.

[01]

O assassino de La Costa foi encontrado na quarta-feira e é um dos assaltantes do posto de gasolina que fica em frente ao terreno invadido. Mas, como ÉPOCA afirmou na semana passada, pouco importa quem apertou o gatilho. Se, por um lado, a morte de La Costa simbolizou a violência embutida na convulsão social que o país enfrenta, por outro deve ser encarada como uma travessia para uma nova fase - na qual o governo deverá agir com mais firmeza e os movimentos sociais com mais prudência. (EP0903, grifos meus)

Nesta semana, Andrei volta à carga. Ele discute o impacto que sua denúncia teve no Congresso e revela com exclusividade, na entrevista da página 40, novas acusações feitas por Zoghbi. Numa conversa gravada, Zoghbi e sua mulher falam com naturalidade em nomes e números relacionados a novos esquemas.

Importante dizer que ÉPOCA não endossa, necessariamente, essas acusações. Ao publicá-las, acreditamos cumprir nosso dever jornalístico de revelar histórias que podem ser fundamentais para o futuro do nosso Legislativo. (EP0909, grifos meus)

Ao utilizar o nome da revista como sujeito da ação verbal, o editorialista dá voz à instituição. Nesse momento, o editorialista realiza um intercâmbio de informações por ele coletadas, e o leitor tem de vê-las ou percebê-las como um traço do coletivo e não apenas do editor. Esse modo de materializar o sujeito reendossa o caráter impessoal do editorial, mas, ao mesmo tempo, estabelece uma interação com o leitor do tipo: "Quem se pronuncia é a revista Época, para você, leitor".

Essa interpretação se verifica contextualmente quando, na oração [01], o texto aborda o fato do assassinato do fotógrafo La Costa que estava a serviço da revista em uma cobertura de invasão de um terreno em São Bernardo. Assim, a retomada do assunto revela o descobrimento do assassino e a presença do sujeito ÉPOCA traz a opinião da revista sobre o fato, sendo que ela deseja um comprometimento do governo para punir o assassino, independentemente de quem seja: sem-terra ou assaltante de banco.

$\mathrm{Na}$ oração [2], o sujeito aparece como forma de manifestar a opinião da revista sobre a informação expressa anteriormente acerca dos escândalos e irregularidades no Congresso, assumindo seu papel como veículo de informação e, simultaneamente, mostrando ao leitor que não está julgando os atos que lá acontecem, mas, revelando que eles se fazem verídicos e 
que precisam ser investigados para que hajam os devidos julgamentos pelas autoridades e, consequentemente, as devidas punições.

Os sujeitos nestas orações intercambiam relações entre o autor e o texto, bem como entre os leitores e os textos, haja vista que, ao passar informação e colocar a revista como agente que desempenha uma ação, teremos a contrapartida desse ato, quer seja pela adesão ao que está aparente no texto, quer pela oposição do leitor à informação. De qualquer forma, o que percebemos é o participante manifesto no sujeito agindo sobre o texto e sobre os participantes do contexto de situação.

Assim como na revista Época, a revista Veja traz o seu nome como sujeito de determinadas orações promovendo interação no fluxo do texto. Vejamos:

VEJA publica nesta edição um levantamento pormenorizado de um fenômeno de alto interesse para quem precisa entrar ou se manter no mercado de trabalho brasileiro. (VE0503, grifos meus)

VEJA é a maior e mais influente revista do Brasil. Com cerca de 1 milhão de assinantes e mais de 200000 exemplares vendidos em bancas todas as semanas, firmou-se também como a quarta maior revista de informação do mundo em circulação. (VE0803, grifos meus)

O sujeito VEJA na oração [03] assume o papel de apresentar o conteúdo da revista ao leitor. Desse modo, ele fala diretamente com aquele que lê a revista, desempenhando seu papel interativo de responsabilidade com o que diz. Além disso, a função que este sujeito desempenha na oração está diretamente ligada a oferta de bens e serviços postulada por Halliday (2004), uma vez que a revista traz um estudo que pode ajudar ao leitor a entrar ou se manter no mercado de trabalho.

No exemplo [04], o uso linguístico do sujeito favorece a uma compreensão de um diálogo entre o texto e o leitor. Em primeira instância, a interação que o sujeito mantém é diretamente com o texto, todavia, a intenção emanada do que é dito se reflete no leitor, pois ele é quem é o responsável pelo crescimento e influência da revista no país. Nesse caso, percebemos uma troca de informação que está condicionada pela proposição declarativa em que o sujeito atua e, como o crescimento da revista depende do leitor, consequentemente, esta informação será aceita pelo leitor da revista.

É notória a questão da responsabilidade que o sujeito assume diante da ação que ele pratica. Tanto nas orações destacadas de Época, quanto nas de VEJA, ocorre essa responsabilidade com a validade da oferta de bens e serviços ou de informações. Halliday (2004) afirma, com relação a isto que, em uma proposta ou proposição, o sujeito faz significar a validade do conteúdo e que esta validade, semanticamente, não está se referindo à verdade ou à falsidade do que é dito, mas ao grau de consenso por validez que aquilo terá entre os usuários da linguagem. Portanto, está claro que o sujeito nominalizado desempenha funções particulares na oração, cumprindo com o papel de interagir, desvelar a autoria e envolver-se com o que diz e para quem diz, porém outros elementos gramaticais atuam similarmente no interior de uma oração, como podemos ver nas desinências verbais de número e pessoa. 


\subsection{Autoria nas Marcas Desinências}

O sujeito gramatical é um elemento que está presente na ação, ainda que sua forma de materialização possa não ser explícita como nos casos já apresentados. Esse elemento também pode ser atualizado por meio das desinências verbais de número e pessoa.

Ao observarmos os editoriais, imbuídos da ideia da impessoalidade, encontramos casos de marcação do sujeito por meio da desinência, comprovando o fato de que as desinências podem, ao marcar o sujeito, apontar a presença do autor e do leitor em um gênero. Tal fato se confirma ao detectarmos, frequentemente, a presença da primeira pessoa do plural (P1p) no gênero editorial. Ainda que as normas regentes desse gênero não permitam o uso da marcação autoral, isso nem sempre acontece, tanto é que editorialistas acabam manifestando-se enquanto sujeitos no texto, como podemos comprovar nos exemplos que seguem:

\section{[05]}

Para acompanhar a reportagem de capa, temos um presente para os leitores: uma ilustração do artista plástico Romero Britto, cedida para ÉPOCA. Britto é um recifense radicado em Miami, que se tornou um sucesso entre celebridades. (EP0109, grifos meus)

\section{[06]}

Importante dizer que ÉPOCA não endossa, necessariamente, essas acusações. Ao publicá-las, acreditamos cumprir nosso dever jornalístico de revelar histórias que podem ser fundamentais para o futuro do nosso Legislativo. (EP0909, grifos meus)

\section{[07]}

Finalmente, não poderíamos deixar de dedicar espaço à notícia da área de saúde mais aterradora da semana: o risco de que a epidemia de gripe suína, oriunda do México, se transforme numa pandemia global com dezenas de milhões de mortos. (EP0909, grifos meus)

Nas orações anteriores em que aparecem destacados os processos ${ }^{2}$ conjugados na P1p (nós), identificamos a interpessoalidade que se mantém, isto é, a relação que se põe entre o autor e o texto. No exemplo [05], ao utilizar o processo temos, o autor mostra o que ele e a redação da revista estão oferecendo ao leitor. O sujeito, nesse caso, estabelece uma distância social em relação ao leitor, deixando-o fora da oração, acontecendo o mesmo com os exemplos [06] e [07].

Os processos acreditamos e poderíamos foram encontrados no mesmo editorial: $O$ congresso, o câncer e a gripe suína. Com o primeiro processo, o editorialista em nome da redação da revista fala da função social do veículo como meio de informação e de denúncia, mostrando que é isso que eles estão fazendo ao apresentar as acusações tecidas pelo ex-diretor do Congresso João Carlos Zoghbi.

\footnotetext{
${ }^{2}$ Como nossa base teórica é a LSF e tomamos dela os termos para fazer um estudo funcionalista da linguagem, adotamos o termo processo em substituição a verbo. Essa posição é baseada na metafunção ideacional da linguagem, na qual as ações de linguagem são processos que refletem as experiências de mundo dos participantes em circunstâncias específicas de uso (HALLIDAY, 2004).
} 
O segundo processo, no exemplo [07], que materializa o sujeito por meio do pronome pessoal nós, embora esteja no mesmo editorial que o exemplo [06] e assume a mesma função interativa entre autor e redação da revista, tem o propósito de informar ao leitor sobre um assunto polêmico que está aterrorizando o mundo: a gripe suína. Como mídia divulgadora de fatos e notícias, a revista sente-se na obrigação de alertar seus leitores sobre esse perigo através de seu editorial. O uso de P1p revela esse compromisso.

Essa forma de materialização do sujeito em que o diálogo estabelecido compreende o autor e o texto promove um distanciamento com os possíveis leitores. Nesse caso, o leitor fica apenas na condição de espectador dos acontecimentos e não como participante ativo da informação divulgada no editorial. Mas, ainda assim, esta é uma forma de interação que a metafunção interpessoal materializa no texto, pois assinala o envolvimento do editorialista com o texto, marcando a expressão da autoria.

Todavia, a utilização da desinência pode também incluir os leitores e, consequentemente, aproximá-los do texto. Vejamos, agora, um caso de relação interpessoal por meio do sujeito que atende a esta última afirmação.

\section{[08]}

Mas - acredite - precisamos parar para respirar e celebrar um fato singelo: a boa saúde financeira de nossos bancos. E, por mais politicamente incorreto que isso pareça, é preciso celebrar o lucro deles. Pois essa é a prova de que nem de longe estamos perto da situação dos Estados Unidos. (EP0509, grifos meus)

A P1p materializada na desinência verbal de número e pessoa dos processos precisamos e estamos realiza um movimento que insere o autor e o leitor no discurso. Essa inserção configura-se, no exemplo, com papel de informação, o que coloca autor e leitor como agentes da situação. Assim, o editorialista fornece informações sobre a crise econômica mundial e o status do Brasil nesse contexto da crise, podendo o leitor tomar essas informações como conhecimento ou acreditar no que o texto transmite.

Desse modo, por meio das modalizações instauradas pelos processos, notamos uma neutralização do autor quanto às informações ofertadas, a fim de não comprometer-se totalmente com o que foi exposto, mas, ao mesmo tempo, esses processos foram estrategicamente utilizados para amenizar a informação de crise que permeia o mundo, e que é de conhecimento geral. Para tanto, o autor do texto ancora-se no fato de que o leitor já possui informações sobre a crise ao compartilhar com ele as informações relevantes acerca do Brasil.

Diante dos exemplos ora analisados, afirmamos que eles atuam pelo sistema de modo (indicativo), por meio de orações declarativas que oferecem informações aos leitores, bem como intercambiam relações com o próprio texto, cabendo aos leitores aderirem ou não ao que é informado, acreditando nas proposições ou as rejeitando. Além do mais, tais informações incidem em marcas de revelação do efeito-autoria no gênero editorial, especificamente verificadas nos processos que estão presentes nesse gênero e que se desvelam pela desinência de número pessoal de $\mathrm{P} 1 \mathrm{p}$.

Até este momento, nos confrontamos com o sujeito em sua forma explícita e com o sujeito marcado na P1p. Neste último caso, o sujeito desempenhou duas funções interativas 
diferentes: a) a autoria é percebida na relação editorialista e instituição, marcando uma relação interna ao texto; e b) a autoria é marcada na/pela relação entre a instituição que inclui o editor e o leitor, havendo, portanto uma parceria extratextual na construção textual. Se para o primeiro, ao internalizar os agentes produtores em um diálogo com o texto, ocorre um distanciamento social entre o produto e o leitor, o contrário acontece com o segundo, pois o sujeito passa, além de compreender o agente de produção interna (o autor), também o leitor na produção. Essa articulação entre autor e leitor aproxima esses interlocutores fazendo-os compartilhar dos mesmos ideais ou informações veiculados no editorial; além disso, ratifica o fato de ser por e para o leitor que o texto se constrói. Nesse sentido, ao ter a adesão do leitor, fazendo com que ocorra a interação na troca de informações, é que o sujeito gramatical desempenha a sua função principal que é de ser o responsável pelo sucesso da oração (HALLIDAY, 2004).

\subsection{Sujeitos pronominais}

Ao discutirmos os pronomes como elementos de marcação do sujeito, vimos que, na Língua Portuguesa, ele pode aparecer sob a forma dos pronomes pessoais retos (correspondentes às pessoas verbais: eu, tu, ele/ela, nós, vós, eles/elas), podemos interpretar a sua materialização no discurso sob a forma dos pronomes possessivos e pronomes de tratamento. Nesse tópico veremos como cada uma dessas categorias se manifesta no editorial realizando a metafunção interpessoal, começando pelos pronomes pessoais.

\subsubsection{Pronomes pessoais}

Os pronomes retos, no interior de um texto editorial, podem exprimir funções diferentes, podendo eles inserir o leitor no que é apresentado/informado, ou colocá-lo como um leitor passivo da informação que o texto veicula. Além disso, de acordo com o uso do pronome, poderemos observar o grau de formalidade que existe na interação entre os usuários da linguagem. Essas funções foram percebidas com base na interpretação do pronome nós, como podemos ver adiante. Sobre a relação que se estabelece entre o autor e o próprio texto, temo o seguinte exemplo:

"Incrível que seja a maior revista do país, mesmo desagradando a tanta gente". Foi uma forma bem-humorada - e exata - de reafirmar o único compromisso da revista: com a verdade, doa a quem doer, para o bem do Brasil. Os anos passam, os governos também, os partidos idem, mas nós continuamos no mesmo lugar. A seu lado, caro leitor. (VE1009, grifos meus)

No exemplo [09], o referido pronome é empregado em um editorial que aborda a concepção partidária acerca do posicionamento político de VEJA. Dessa forma, o nós, ao fim da oração, realiza sua função interpessoal através do sistema de modo trocando bens e serviços, uma vez que mantem uma relação direta entre o autor e o texto.

Portanto, ao estabelecer essa relação texto e autor/instituição, ocorre um distanciamento em relação ao leitor, uma vez que esse passa a ser um receptor e não um agente no processo de produção, bem como mantém uma impessoalidade ao figurar nas orações somente a opinião 
institucional. Todavia, o pronome pessoal reto nós, exerce outra função que é a de incluir o leitor, atenuando o caráter impessoal que é intrínseco ao gênero.

Se levarmos em conta os 365 dias do ano e uma carga de impostos equivalente a - de acordo com as últimas estimativas - algo como $36,5 \%$ do Produto Interno Bruto (PIB), então o Brasil trabalha apenas para o governo do dia $1^{\circ}$ de janeiro ao dia 25 de maio. Em seguida, começamos a trabalhar para nós. (EP1109, grifos meus)

Cortes de impostos, acompanhados de uma profunda reforma do Estado, significariam mais recursos circulando no mercado, em vez de ser engolidos em atividades desnecessárias para o país. Significariam, em suma, mais dinheiro na mão de quem sabe como gastá-lo - nós mesmos. É essa a lição do singelo exemplo das filas nos postos de gasolina. (EP1109, grifos meus)

Nos exemplos [10] e [11], retirados do editorial O Estado continua sendo o problema, o pronome usado no texto refere-se tanto ao autor, quanto à instituição e ao leitor, uma vez que, ao falar de tributação, de impostos e do controle de finanças, é sugerido no texto que quem melhor sabe gastar o dinheiro público não é o Estado e, sim, o povo. Essa opinião apresentada no editorial, através de proposições declarativas que realizam troca de informação, é disposta como algo consensual e, ao fazer dessa maneira, ocorre um menor distanciamento entre leitor, texto e autor. Portanto, as informações trocadas tendem a ser aceitas pelo público leitor devido essa relação mais pessoal que se estabelece pela presença do pronome pessoal de P1p.

Nos exemplos analisados, notamos que o pronome pessoal reto é um recurso de interação no texto, haja vista realizar a função de intercambiar relações e informações. Notamos, também, que o uso desse pronome acentua o grau de formalidade do gênero. Ou seja, o editorial passa a ter uma linguagem menos formal em determinados casos por aproximar os participantes da ação.

\subsubsection{Pronomes possessivos}

Seguindo a análise interpessoal da linguagem por meio dos pronomes, observemos, agora, os pronomes possessivos ${ }^{3}$.

A repórter especial Eliane Brum é um caso que merece exame: acumulou 25 prêmios em pouco mais de década e meia de profissão. Só em 2002 Eliane ganhou três troféus de primeira linha, por três reportagens diferentes - o Líbero Badaró, o Wladimir Herzog e o Prêmio da Federação das Indústrias do Rio de Janeiro. Nossa sucursal de Brasília também reúne jornalistas com muito apetite para esse tipo de mercadoria. São seis profissionais, 15 prêmios de relevo. (EP0103, grifos meus)

\footnotetext{
${ }^{3}$ Cabe esclarecer que não tomamos todos os pronomes possessivos que aparecem no editorial, mas observamos aqueles que se apresentaram com maior frequência, assim como fizemos com os demais recursos de interpessoalidade detectados na linguagem verbal, uma vez que essa foi a metodologia utilizada e que contribui significativamente para nosso objetivo de perceber as relações interpessoais no editorial. Nesse caso, tomamos para análise os pronomes: nosso, nossa, nossos e nossas.
}

Work. Pap. Linguíst., 13(3): 64-81, Florianópolis, ago/dez, 2013 


\section{[13]}

No ano passado, a equipe de arte da revista ganhou um Esso, num reconhecimento por nosso trabalho de diagramação, marca registrada desde o lançamento. No Rio de Janeiro, a fotógrafa Mirian Fichtner, autora de uma imagem que correu o mundo - de um assaltante com o revólver na boca de sua vítima no interior do ônibus 174 -, acumulou cinco prêmios, três internacionais. (EP0103, grifos meus)

Nos exemplos anteriores, os pronomes possessivos (nossa, nosso) referem-se ao editor, as reportagens e a própria revista. Desse modo, a interpessoalidade se manifesta textualmente, uma vez que o autor se marca pelos pronomes. Portanto, ao ler o texto, o leitor sabe de que se está falando, como acontece no uso do pronome nossa, exemplo [12], em que o editor referese a sucursal que é integrada a matriz da revista da qual ele faz parte. No uso seguinte, exemplo [13], o pronome nosso é utilizado para incluir o autor no merecimento do prêmio ganho pela revista. Desse modo, os pronomes aparecem em orações declarativas que oferecem informações sobre a revista e seus títulos angariados ao longo do tempo.

Como observamos, todos os elementos analisados estão sempre em uma interação entre autor e texto e/ou entre leitor e autor, bem como aconteceu com o pronome pessoal reto nós. Com os pronomes possessivos não é diferente. Vejamos:

Dificilmente as novas descobertas tornarão a busca do parceiro ideal uma questão científica - até porque a maioria das pessoas adora o velho método da tentativa e erro. Mas elas podem nos ajudar a acertar mais e nos arrepender menos em nossas escolhas. (EP0109, grifos meus)

O pronome nossas manifestado na oração [14] estabelece uma ponte entre o editor e o leitor. Nesta oração, ele coloca em nível de paridade os envolvidos na busca pelo amor, assunto discutido no editorial. Neste caso, o pronome atua estabelecendo uma troca de informações entre os usuários da linguagem por meio do sistema de modo, assim, o pronome possessivo desempenha o papel de diminuir o grau de formalidade e impessoalidade no gênero editorial e fornecer informações que, provavelmente, serão aceitas pelo leitor.

Diante disso, ao passo que o uso do pronome possessivo pode afastar os agentes do processo de produção textual, também pode proporcionar o contrário. Curiosamente, de uma forma ou de outra, atinge o propósito da metafunção interpessoal realizada no sistema de modo que é tornar o evento interativo (HALLIDAY, 2004), ou seja, os pronomes possessivos estabelecem diálogos entre autor e texto, colocando o leitor fora da enunciação, bem como unindo o leitor ao que está sendo proferido no texto. Com base nessas análises, percebemos a similaridade de uso que as formas pronominais, em cada uma de suas classificações, desempenham no gênero editorial, ou seja, tanto os pronomes pessoais, quanto os pronomes possessivos promovem, semanticamente, a marcação da autoria, bem como graus diferentes de formalidade e de envolvimento entre os usuários da linguagem.

\subsubsection{Pronomes de tratamento}

A última categoria pronominal que observamos nos editoriais foram os pronomes de tratamento. $\mathrm{O}$ único encontrado é o pronome você. Com base nas análises, percebemos que a 
função desempenhada por esse recurso é a de marcar o leitor no texto e ao mesmo tempo estabelecer um diálogo entre autor e leitor. Vejamos:

Experimente fazer o teste: num jantar entre amigos ou numa festa, diga que foi assaltado recentemente. Não precisa nem contar detalhes. É como se você estivesse apertando um botão invisível, que faz todo mundo ao redor contar alguma experiência. (EP0503, grifos meus)

[16]

Mais duas reportagens poderiam também ter sido elevadas à categoria de capa. [...] Só um único assunto pode ser capa, mas todos estão na revista que você tem nas mãos. (VE0509, grifos meus)

O pronome voce, nos dois excertos, surge como meio informal de manifestar linguisticamente o leitor, uma vez que, aparentemente, o texto simula o desenrolar de um diálogo que vem ocorrendo durante o fluxo textual, embora isso não aconteça.

No primeiro caso, o pronome é introduzido após uma sugestão que o autor faz ao leitor para que ele realize entre amigos de contar que foi recentemente assaltado, assim, o você é uma forma de chamar a atenção do leitor para o que acontecerá se ele acatar a sugestão. No segundo, o pronome é evocado para manter uma relação de mais proximidade e de diálogo com o leitor que se interessa pelas reportagens que são contempladas na edição da revista e a reportagem que garante o privilégio de ser capa.

\section{CONSIDERAÇÕES FINAIS}

Ao implementarmos as análises acerca da interação, autoria e envolvimento no gênero editorial, verificamos a ideia central postulada pela LSF na qual o sujeito é responsável pelo sucesso da oração (HALLIDAY, 2004). De acordo com as interpretações feitas, esse elemento gramatical pode reendossar o caráter de impessoalidade do gênero editorial por manifestar uma posição institucional e não uma opinião particular. Entretanto, com as proposições elaboradas com os sujeitos VEJA e ÉPOCA, notamos uma oferta de informação, o que exige, em contrapartida, a adesão ou contrariedade ao que é informado, ocasionando, portanto, um grau mínimo, porém existente entre leitor e texto. Além disso, ao usar o sujeito na oração, percebemos que ocorre uma tomada de responsabilidade por parte desse sujeito sobre o que é informado, ou seja, ele valida a informação como algo consensual entre os usuários da linguagem. Nesse sentido, como o sujeito está vinculado à oferta de informação, constatamos que a sua responsabilidade está em conduzir o andamento textual, estabelecendo diálogos entre os interlocutores do gênero editorial.

Com as desinências verbais, especificamente as de $P 1 p$, notamos dois tipos de envolvimento no gênero editorial. $\mathrm{O}$ primeiro diz respeito à relação produtor e produto, no qual o diálogo se instaura entre quem diz e o que é dito, revelando o compromisso do autor e da instituição através de proposições declarativas. O segundo diz respeito à relação que o leitor ocupa dentro do texto, pois, como vimos, há momentos em que o editorialista faz uso da P1p para dispor a informação como sendo algo compartilhado consensualmente por todos os interlocutores. Nos dois casos, respectivamente, foram verificados níveis distintos de interação com o leitor, ora distanciando-o da informação, ora apresentando-o como agente de produção da informação. Além disso, percebemos que a neutralidade e impessoalidade que 
são características do editorial padrão (MELO, 2003) não são tão características dos editoriais de revistas de informação, pois, ao passo que a desinência verbal é utilizada, desvela-se a presença do autor na opinião ou apresentação tecida no texto editorial.

A categoria pronominal, em suas diversas nuances, apresentou-se como elemento léxicogramatical e textual que marca a presença do sujeito no gênero editorial. A utilização do pronome pessoal nós, assim como das desinências verbais analisadas, cumpre o papel de intercambiar informações e interação entre os usuários da linguagem. Desse modo, as funções desempenhadas por este mecanismo são idênticas às das desinências verbais, ou seja, por meio do pronome pessoal podemos observar a marcação da autoria no texto, diminuindo o caráter impessoal do gênero editorial, bem como a presença do leitor nas proposições, o que implica diretamente em uma aproximação entre o leitor e o texto, acentuando o grau de informalidade da informação veiculada. No entanto, o sujeito pronominal torna mais saliente a presença autoral no gênero investigado.

Quanto aos pronomes possessivos analisados, verificamos que eles são empregados no gênero editorial para se referir ao produtor do texto, às reportagens e à própria revista em primeira instância. Noutro momento, esses pronomes podem se referir a um conjunto de pessoas que compartilham um interesse comum, ou agem de uma mesma forma. Essas constatações estão respaldadas nas diversas trocas de informações que se mantiveram no gênero editorial por meio deste recurso da linguagem. Aliás, por meio dos pronomes possessivos também observamos a presença do autor no texto (quando o uso girava em torno da relação autor versus texto) e a presença do leitor no texto (quando o pronome era utilizado como forma de exprimir um pensamento comum dos participantes da situação comunicativa, isto é, a informação veiculada no texto tanto é pensamento do leitor quanto do autor).

No gênero editorial, diferentemente dos demais recursos léxico-gramaticais anteriormente apresentados, os pronomes de tratamento não visam a marcar a voz de quem fala no texto. Pelo contrário, esse recurso marca no texto o interlocutor, ou seja, aquele para quem se está falando. Desse modo, o pronome de tratamento você, em nossa interpretação sugere uma informalidade e aproximação social entre os participantes da prática discursiva, uma vez que tal uso exprime certo grau de intimidade entre os interlocutores.

Por fim, constatamos que o sujeito e as demais formas de marcação da pessoa gramatical têm um importante papel, realizando a troca de informações e, por conseguinte, realizando interação entre os envolvidos a situação de comunicação, uma vez que revelam graus diferentes de formalidade, bem como, atenuam o caráter impessoal do gênero editorial, devido ao fato de que a autoria é revelada por elementos linguísticos determinados que são agenciados pelo gênero, em dado contexto de situação.

\section{REFERÊNCIAS}

AQUINO, L. D. de. Mecanismos de construção de sentidos no gênero editorial: aspectos verbais e visuais. Pau dos Ferros: UERN, 2010. (Dissertação de Mestrado), inédita.

BECHARA, E. Moderna gramática portuguesa. 37 ed. ver. e ampl. Rio de Janeiro: Lucerna, 2004.

BUTT, D. et. al. Using Functional Grammar: an explore's guide. Second Edition. Sydney: Macquarie University, 2001. 
EGGINS, S. An introduction to Systemic Functional Linguistics. London: British Library, 2004.

GHIO, E.; FERNÁNDEZ, M. D. Linguística sistémico funcional: aplicaciones a la lengua española. Santa Fé: Universidad Nacional del Litoral, Waldhuter Editores, 2008.

HALLIDAY, M.A.K. An introduction to Functional Grammar. First edition. London: Edward Arnold, 1985 [1994]. . An introduction to Functional Grammar. 3rd edition. Rev. London: Arnold, 2004.

; MATTHIESSEN, C. M. I. M. Systemic Functional Grammar: a first step into the theory. 1997. Disponível em: <http://whgsoft.com/siystemic/index.html $>$. Acesso em: 13 de jun. de 2005.

MARTIN, J. R. et al. Working with Functional Grammar. London: Arnold, 1997.

MELO, J. M. de. Jornalismo opinativo: gêneros opinativos no jornalismo brasileiro. Campos do Jordão: Mantiqueira, 2003.

SOUZA, M. M. de. A autoria em editoriais jornalísticos: uma abordagem sistêmicofuncional. 2007, online. Disponível em: $<$ http://www3.unisul.br/paginas/ensino/pos/linguagem/cd/Port/95.pdf $>$. Acesso em: 9 de agosto de 2008.

\section{REFERÊNCIAS DOS EDITORIAIS ANALISADOS}

Continuamos no mesmo lugar. Veja, São Paulo, Ed. 2113, Ano 42, n. 20, 20 de maio de 2009.

Duas capas, a mesma VEJA. Veja, São Paulo, Ed. 1811, Ano 36, n. 28, 16 de julho de 2003.

Entre o amor e a guerra. Época, São Paulo, n. 556, 12 de janeiro de 2009.

Insegurança para todos. Época, São Paulo, Globo, n. 263, 2 de junho de 2003.

O Congresso, o câncer e a gripe suína. Época, São Paulo, n. 572, 4 de maio de 2009.

O Estado continua sendo o problema. Época, São Paulo, n. 576, 1 de junho de 2009.

Os bancos daqui - e os lá de fora. Época, São Paulo, n. 563, 2 de março de 2009.

Otimismo contra a crise. Veja, São Paulo, Ed. 2102, Ano 42, n. 9, 4 de março de 2009.

Pela porta estreita. Veja, São Paulo, Ed. 1805, Ano 36, n. 22, 4 de junho de 2003.

Políticos e críticos. Época, São Paulo, n. 272, 4 de agosto de 2003.

Profissionais premiados. Época, São Paulo, n. 255, 7 de abril de 2003. 